\title{
Entrevista com Michaël Oustinoff
}

\section{Interview with Michaël Oustinoff}

\section{Álvaro Faleiros*}

Álvaro Faleiros: Estou aqui com o Michael Oustinoff, vou entrevistá-lo, perguntando um pouco sobre a trajetória dele e as pesquisas que ele está realizando. Para começar, como você se formou, se interessou pela tradução, como foi que começaram seus estudos pela tradução?

Michael Oustinoff: 0 que me interessou na tradução é que a tradução não interessava aos meus professores, e eu não percebia por quê. Eu comecei no Liceu; eu me formei em inglês, no departamento de inglês e as disciplinas eram a literatura, linguística e civilização (quer dizer, a história da civilização britânica, americana, etc.), então a tradução fazia parte do currículo, mas não como teoria. Era uma coisa a mais - ou a menos. Antes de ir, portanto, à faculdade, eu tinha lido a tradução das obras de Edgar Allan Poe por Baudelaire e eu achava mesmo extraordinária a análise da passagem de uma língua para outra feita pelo Baudelaire, e quando cheguei à faculdade, pois, como nos diziam, é que quando se começa realmente a bem falar e a bem ler o inglês, as traduções não serviam nada. E eu não percebia por que que a tradução do Baudelaire, de repente, tinha que ser deitada fora. E eu não sabia em que direção ir, mas eu tinha duas soluções: a primeira era fazer uma tese sobre o Nabokov, porque tínhamos estudado o romance Ada, que ele escreveu em 1969 misturando o francês, o russo e o inglês, e é muito interessante, é um livro, afinal, que antecipa a globalização de hoje.

\footnotetext{
* Graduação em Ciências Sociais pela Universidade Estadual de Campinas (1994), mestrado em Lingüística - Université du Québec à Montreal (1998) e doutorado em Letras (Língua e Literatura Francesa) pela Universidade de São Paulo (2003). É professor de Literatura Francesa da USP. Tem experiência na área de Poesia e Tradução, atuando principalmente nos seguintes temas: tradução, poética comparada e poesia. É também tradutor e poeta. E-mail: faleiros@usp.br
}

TradTerm, São Paulo, v. 33, junho/2019, p. 168-177 
Mas ao mesmo tempo, em 1987 ou 85, houve um livro que foi publicado em francês, por um escritor francês de pais americanos, Julien Green, que me interessou particularmente. O livro chamava-se Le Langage et Son Double, em duas línguas, em inglês e em francês, e ele traduzia-se ele próprio no domínio literário, além dos ensaios, e também havia uma reflexão, que seria parte do livro, sobre o que era pertencer a duas línguas, duas culturas diferentes, portanto, o que era ser bilíngue e o bilinguismo de escritura. E então isso foi o que eu preferi, fazer uma tese sobre o bilinguismo de escritura e a autotradução.

Era um domínio em que havia muito poucas pesquisas quando eu comecei, nos anos mil novecentos e oitenta e tal, e agora, quando eu acabei a tese em 1996, no espaço duns vinte anos, onde só havia umas dez ou umas vinte pesquisas sobre o assunto, agora são mais de mil e os translation studies ou a tradutologia agora estão a criar uma subdisciplina que se chama autotradutologia. Portanto é uma mudança incrível, eu não sabia que essa área da pesquisa seria tão forte, mas agora é verdade que, ao fim e ao cabo, as coisas mudaram muito. Antes, a tradução, pelo menos na França, não interessava a muitos; agora, há um desenvolvimento dos estudos da tradução, primeiro no Canadá, nos países anglo-saxônicos, e agora no Brasil, também. Se eu percebi bem houve uma espécie de revolução nesse aspecto das pesquisas, de prática também da tradução, em vários outros países. O que me fascina é o fato de que uma disciplina relativamente periférica - pois tal movimento começou nos anos de 1990, a tradução e a teoria da tradução eram periféricas -, mas com a globalização, agora estão no centro. Não só, claro, aos pesquisadores de tradução, mas também para pessoas que estão em outras áreas disciplinares: historiadores, como nos Estados Unidos; os especialistas das ciências da comunicação, os Communication Studies; os filólogos, quer dizer, tantas disciplinas que não costumavam se comunicar entre si, de repente, por causa dessa evolução histórica, estão cada vez mais interessadas em cruzar suas pesquisas, pode ser do ponto de vista da história, pode ser da literatura comparada, etc. Portanto eu não sabia, quando eu tinha começado a me interessar pela tradução, que haveria um interesse tão grande agora, o que é uma boa notícia para as pessoas que começam a fazer pesquisas nessa área, porque há muitos assuntos diferentes para ter direções de pesquisas pessoais e com os estudantes também, o que é bastante reconfortante.

AF: Nesse contexto, você tem desenvolvido várias pesquisas, e elas começaram com a autotradução. Você já comentou um pouco sobre esse seu trabalho de doutorado. Esse 
trabalho virou um livro, também. Você poderia comentar um pouco sobre a publicação desse livro, alguma especificidade sobre esse livro, ou sobre a circulação dele?

MO: Sim, eu defendi a minha tese de doutoramento em 1996 e, logo a seguir, em 1997, eu entrei como professor associado na Sorbonne em Paris. E o livro foi publicado, quer dizer, a visão dessa tese de doutoramento foi publicada em 2001, em Paris, pela editora L'Harmattan, e foi um livro muito lido, porque apesar de não ter sido traduzido para outras línguas, por enquanto, até que foi comentado em várias línguas, em português, em inglês e, portanto, é considerado (foi o que me disseram, claro) como uma das obras pioneiras no campo. Não havia nada, então foi uma espécie de síntese da área e então, pouco a pouco, os estudos foram juntando-se uns aos outros. A princípio houve críticas, como sempre, às vezes exageradas num lado ou do outro, mas ao fim e ao cabo considera-se que é um livro que tem que ser consultado no princípio, quando se faz pesquisas sobre a autotradução.

O meu ponto de partida é a literatura, como eu disse, eu queria ter feito uma tese sobre o Nabokov, mas afinal foi também o que eu fiz, porque ao princípio eu queria trabalhar só com o inglês e o francês, porque eu estou no departamento de inglês, portanto com Beckett essencialmente e o Julien Green, mas quando eu vi que faltava matéria para acabar eu juntei o Nabokov, com o inglês e o russo, e afinal acabei por fazer também outra tese que eu queria fazer. E, portanto, em 2017, eu fui convidado a São Petersburgo, no museu Nabokov. O Museu Nabokov é a casa que a família Nabokov tinha em São Petersburgo, com os especialistas do mundo e principalmente russos, onde eu pude comparar as minhas análises às análises dos especialistas em Nabokov e as coisas acertavam-se, o que é interessante. É um livro agora cada vez mais utilizado, ao que me dizem, então agora o problema é que eu tenho que responder às perguntas que me fazem. Só pra acabar nesse assunto, várias pessoas me disseram "muito obrigado pelo seu livro, porque foi interessante para as minhas pesquisas, para o meu próprio doutoramento", e eu não sabia ao princípio que o meu trabalho ia servir a outros. Mas ao mesmo tempo não é assim tão estranho, afinal, eu parti do cânone literário, como Beckett e o Nabokov, mas com a globalização, há muitos outros autores menos conhecidos que eles, mas com a mesma problemática: eles têm que mudar de língua, porque foram forçados ou por gosto. Por exemplo, Beckett não conseguia escrever em inglês alguma coisa, portanto o francês pra ele foi uma maneira de encontrar-se a si próprio. O Nabokov foi forçado pelas circunstâncias históricas a mudar de língua, etc. Então, só esses dois casos, não é? Há muitos mais como eles. Pessoas que mudam, ficam, estão, sentem-se prisioneiros de 
uma língua onde eles não conseguem fazer alguma coisa de interessante e outros ainda são forçados; já com essas duas configurações há muitos, milhares de autores pelo mundo afora que escrevem e exprimem-se em várias línguas. $E$ também pode ser estendido a pessoas que não são, a bem dizer, escritores: por exemplo nas ciências sociais, filósofos, acadêmicos em geral, cada vez mais eles têm que traduzir-se ou serem traduzidos em outras línguas por causa da divulgação das pesquisas, que agora é internacional, e isso precisa ser feito em várias línguas, portanto esse é um alargamento da perspectiva que é especialmente interessante.

AF: Existe alguma especificidade que você identificou na autotradução que a difere de uma tradução feita por outra pessoa?

MO: Eu queria fazer, como diz o Antoine Berman, uma crítica positiva da tradução. E é por isso que havia poucas pesquisas na autotradução, porque as pessoas diziam "mas a autotradução não é uma tradução. Não é, é outra coisa", e então eu cheguei à conclusão que era e não era, quer dizer, uma parte, por exemplo, o Nabokov, quando traduziu-se do russo para o inglês, ele pedia para um tradutor fazer uma primeira versão literal e depois ele modificava quando não estava contente com essa tradução literal. Portanto as autotraduções em inglês são uma parte que não difere do que um outro tradutor teria feito. Nabokov até traduziu outros autores, como Lermontov, Pushkin, etc. E a mesma coisa com o Beckett, há muitas partes onde é impossível, se tirarem o nome Beckett ou Nabokov, fazer a diferença entre a tradução deles e uma tradução feita por outras pessoas. Portanto, há uma parte, e bastante importante, onde eles traduzem como um tradutor, como eu disse, alográfico, quer dizer, como se fosse um outro, e não si próprio. Agora, também há uma parte onde eles são autores, portanto eles podem transformar muitas coisas que agora não é possível ao tradutor. O tradutor não pode dizer, como Voltaire no século XVIII, "Shakespeare é um bom ator, mas há coisas que não são bem escritas e eu vou melhorar". Raras são as pessoas que dizem isso e que podem fazer isso. Eles transformam isso porque são autores, mas ao mesmo tempo, ainda é uma tradução. Vão modificar, por exemplo, o estilo, vão modificar metáforas aqui e ali, etc., fazer transformações que não são assim tão espetaculares, e há uma terceira forma de autotradução que é a tradução recreativa. Aí é diferente, é um autor que está a transformar partes importantes de sua obra. Portanto essas são as três coisas ao mesmo tempo: a autotradução é uma forma de tradução, mas pode ir além do que geralmente é concebido como uma tradução. Aí é que é muito interessante, porque a autotradução tem também um fundamento teórico 
interessante, que se chama a ontologia da obra. A questão, por exemplo, segundo Goldmann, considera que a obra literária, como a obra artística, tem que ter um lugar, tem que ser localizada. Por exemplo, uma obra literária é original e, portanto, a tradução não é a obra, é outra coisa. Já o Gerard Genette não está de acordo: ele diz que as traduções também são a representação da obra, pertencem à obra como versões da obra e não são uma coisa de fora. E um dos argumentos que ele avança são as autotraduções, ninguém pode dizer que as autotraduções do Beckett não são traduções. E se são traduções, quer dizer que a obra também é representada pelas traduções do Beckett e do Nabokov, e então a tradução faz parte, é apenas uma versão da obra original. Portanto foi isso que eu achei importante dizer: o que fazem o Beckett e os autotradutores são traduções. E toda essa parte, pode ser $80 \%$, às vezes, de um livro, é feita em colaboração ou de maneira totalmente igual ao que fazem os outros tradutores. Nesse caso é simples, é como o tradutor, conhecido ou não, a partir do momento onde ele faz uma boa tradução, não há razão considerar que é uma versão má da obra. É uma versão integrante da obra. Portanto toda a minha tese é uma forma de crítica positiva da tradução, e não somente da tradução feita pelo próprio autor.

AF: Muito obrigado. Em seguida, depois do doutorado, você foi convidado para fazer um livro de introdução de apresentação da tradução na coleção Que sais-je, chamado La Traduction, que inclusive está traduzido no Brasil, também. Você poderia comentar um pouco sobre a gênese dessa obra, quais foram os principais princípios organizadores, os grandes eixos que você considerou fundamentais para introduzir alguém no tema da tradução?

MO: Sim. Quer dizer, o Que sais-je tem uma história bastante associada a muitas pessoas. Eu queria escrever um terceiro livro, que foi publicado mais tarde, mas eu tinha um projeto que tinha sido mandado à editora do PUF- Presse Universitaire de France, que disseram “não, agora a nossa política editorial não permite publicar o tal projeto, mas nós estaríamos muito interessados se aceitasse de fazer um Que sais-je sobre tradução". Claro, eu disse sim, e foi um projeto muito interessante, porque eu tive mesmo que alargar as coisas, não era só a tradução literária, porque tinha que abranger todos os campos da tradução, primeiro, e a história da tradução também é muito importante, os métodos, a seguir e claro, não podia fazer um livro sobre tradução unicamente com o francês e o inglês, portanto tive que alargar a perspectiva. E foi uma surpresa muito agradável ver que um livro sobre tradução foi traduzido, por exemplo, em japonês e, claro, na minha língua materna, o português, no Brasil. O Que 
sais-je foi publicado em 2003 e foi traduzido para português do Brasil em 2011, e para mim foi uma grande satisfação saber que o livro tinha sido traduzido no Brasil e eu aprendi, há poucos dias, que afinal é um livro que é muito utilizado nas universidades brasileiras, o que é um privilégio. E até, como eu leio, claro, o português, eu li essa tradução; eu teria traduzido de uma maneira diferente, mas não quer dizer que a tradução que existe seja má, é só que não há duas traduções iguais possíveis, e essa é uma tradução muito interessante porque é como se eu fosse traduzido dentro da minha língua materna, de português de Portugal para português do Brasil, o que é muito interessante, pois o contexto é diferente. No fundo é o mesmo livro, mas ao mesmo tempo, como é que eu hei de dizer, o significado dele, em grande parte, tira-se do fato de que foi contextualizado no contexto brasileiro. O que eu acho bastante interessante. Em 2003, o Dominique Wolton, que é uma pessoa que trabalha no centro nacional da pesquisa científica (CNRS), na área das ciências da comunicação, e ele nessa altura estava à procura de alguém que pudesse fazer pesquisas na área de tradução e globalização.

AF: Inclusive essa é a próxima pergunta, porque depois dessa experiência de síntese das reflexões sobre a tradução para iniciantes, para introduzir o assunto, houve esse convite para que você trabalhasse com a tradução e globalização, e que também, pela própria maneira que você falou, você tem uma formação, uma história de vida que já é um exemplo mesmo dessa globalização. Então se você pudesse ao mesmo tempo falar um pouco dessa sua história de vida com as línguas e dessa sua pesquisa sobre tradução e globalização, eu imagino que de uma certa maneira uma coisa inspire a outra.

MO: Sim, quer dizer, não é só o meu caso pessoal, mas eu acho que a tradução era periférica, não é? E também as línguas, pelo menos num país como a França, eram uma coisa que era considerada secundária, uma coisa que não era assim tão importante, mas com a globalização, a questão das línguas foi se tornando mais central e as pesquisas, o trabalho científico sobre as línguas do mundo, a comunicação em várias línguas e a tradução, de periféricos também se tornaram centrais. E então, de uma certa maneira, pessoas como eu, nascidas nos anos cinquenta, já nasceram numa globalização potencial que só se realizou muitos anos depois, porque houve várias mundializações na história. Há pessoas que falam da primeira mundialização, em como a espécie humana, ainda 10.000 anos antes de Jesus Cristo, foi se espalhando pelo planeta. Mas a última mundialização é o que se chama de globalização, com as tecnologias, como também por exemplo no desenvolvimento de países como o Brasil, 
como a China, como a Índia novamente, quer dizer, é também a desocidentalização do mundo. Com o mundo multipolar, já não é o Estados Unidos e somente os Estados Unidos e o Ocidente no centro, mas há vários centros. Com essa história a transformarse, os países estavam apartados uns dos outros e agora há essa interconectividade mundializada, globalizada, e isso é que explica que esse interesse pelas línguas, pela comunicação e pela tradução seja assim tão forte. E foi o que se deu no meu caso. É verdade que eu nasci em França, mas de uma mãe que nasceu em Portugal, de um pai que nasceu na Rússia. Portanto, os meus imaginários eram franceses, porque eu era francês, mas também portugueses e russos, mas isso era uma coisa que ficava de lado. E pouco a pouco, eu comecei a aprender as línguas por mim próprio quando era novo. Depois do Latim e do Grego na escola comecei a me interessar pelo Alemão, pelo Russo, etc. Então uma coisa que eu pensava que nunca ia servir a seja o que for, afinal teve um interesse, uma importância realmente extraordinária. Só uns poucos exemplos: uma colega na Sorbonne, de História, convidou-me pra dar uma fala a estudantes de doutoramento e o que ela disse foi "o nosso colega Michael Oustinoff vai agora falar de tradução. Para nós, especialistas de História de Transferências Culturais, a tradução é central". Mesma coisa, por exemplo, quando fui convidado a trabalhar no CNRS, com o Dominique Wolton, com o tema tradução e globalização. Era evidente que tudo o que eu tinha afinal estudado nessa maneira paralela agora era central, o fato de eu poder falar Português, Inglês, Francês, Russo, Alemão, etc., comunicar-me em todas essas línguas, e ler, sobretudo, tudo isso, na internet, é uma coisa positiva e não é mais uma coisa periférica. Portanto, no CNRS, que era e é ainda um grupo de trabalho fantástico porque é interdisciplinar, eu posso falar com filólogos como a Barbara Cassin, com sociólogos, com especialistas da comunicação, até com os especialistas de química ou de física nuclear e todos eles estão interessados pela questão da comunicação globalizada através das línguas. Uma coisa que mudou radicalmente nesse aspecto é a internet. De 1995 aparece no Brasil, e de 1995 até os anos 2000, 90\% da internet era em inglês, e agora, num espaço só de 10 anos, na primeira década do século XXI, a parte do inglês compreende menos de 30\%. Quer dizer que agora para uma pessoa que quer ser informada do que está a passar na internet, o inglês não chega, e os anglófonos estão agora a par disso, estão bem conscientes que o mundo de hoje é um mundo onde o inglês, claro, é muito importante, mas as outras línguas são muito importantes também, quando, por exemplo, a Wikipedia tem mais de 200 línguas. E como uma pessoa não pode, claro, aprender todas as línguas, para formular o que diz o Umberto Eco acerca da língua da União Europeia, ele diz um tanto a brincar mas meio sério, que a língua da União Europeia é a tradução. A mesma coisa posso 
dizer agora da globalização, a língua da globalização não é o inglês, ou é também o inglês, mas primeiro, a língua das línguas da internet é a tradução. E uma coisa que se vê ainda melhor agora com os desenvolvimentos dos softwares de tradução automática, que são uma ajuda também para as pessoas que não têm acesso a notícias em línguas que eles não conhecem, portanto aí há uma dinâmica extraordinária no que diz respeito a essa questão.

AF: Então os computadores serão os tradutores do futuro?

MO: Umas duas semanas atrás eu dei uma conferência em França sobre esse tema. Quer dizer, é sempre a mesma coisa, no CNRS nós somos muito críticos dessa importância do tecnicismo. Há muitas pessoas que dizem "pronto, as máquinas, os computadores vão mudar tudo", até há pessoas que pensam que o espírito vai ser absorvido pelos computadores, etc. As pessoas vão poder ter competências extraordinárias com coisas que vão ser integradas ao corpo, etc. Nós, não. Para mim isso é mais um sonho que a realidade e até as vezes um pesadelo. Mas não, como dizia um filósofo alemão: "Technik ist nur ein Mittel", a técnica é só um meio, não é um fim em si. Portanto é como um carro, claro, ou um avião: é só um instrumento. $E$ as novas tecnologias podem ser fascinantes, mas são só um instrumento. Com a tradução é a mesma coisa, não é como em Star Trek ou nesses filmes de ficção científica, o tradutor universal, como a Microsoft está a tentar vender. Ainda na internet dizem que o Star Trek se passa no século XXIII mas eles já têm a tecnologia no século XXI, mas não é, não. Eu já comecei também com os estudantes a utilizar esses programas de tradução assistida por computadores. É um instrumento. É sempre preciso que haja alguém que perceba bem essa questão de línguas de comunicação intercultural e tradução pra rever um texto, se não nunca se chega a uma qualidade de tradução ou de interpretação que seja boa. Como um último exemplo, eu lembro muito bem, era antes da internet, portanto estou a falar do neolítico inferior, nos anos 1980 e tal, havia uma pessoa que era perfeitamente bilíngue, americana e francesa, e trabalhava pro público, numa cidade francesa. Ela foi mandada a Chicago, para os Estados Unidos, pra falar de programas de organização, como eles faziam em Chicago e ela deveria voltar a França pra dizer "pronto, em França nós podemos utilizar certas coisas que foram feitas lá, outras não, etc.”, para analisar a situação lá nos Estados Unidos. Quando ela chegou e viu que tinha uma intérprete ao lado, ela pensou: “mas por que eu preciso de uma intérprete, eu falo, eu sou perfeitamente bilíngue, o inglês também é minha língua e eu conheço pessoas nos Estados Unidos, conheço perfeitamente os estados 
Unidos, por que eu vou precisar de uma intérprete?”. Mas ela percebeu, quando a discussão começou a ser técnica, que havia palavras que ela não conseguia ter em inglês, porque não estava habituada e não tinha formação de intérprete, então não conseguia ter as palavras, a maneira de falar técnica. Em francês, conseguia, mas a intérprete falava muito melhor, conseguia exprimir as mesmas coisas, mas muito melhor do que ela. Foi aí que ela percebeu o interesse de uma pessoa - porque agora fala-se de tradutores não-humanos, mas os seres humanos são sempre importantes, ou então, mesmo a supor que as máquinas possam realmente fazer traduções extraordinárias, como diz o Nelson Mandela, quando se fala a uma pessoa numa língua que ela perceba, falamos à cabeça dela, mas quando falamos na língua dessa pessoa, falamos ao coração. Uma máquina não pode falar ao coração de ninguém e, portanto, à dimensão humana, a não ser que as máquinas possam ser também, ter filhos, sei lá, desesperos e sonhos e pesadelos.

\section{AF: Sentir na pele.}

MO: Sentir na pele, etc. O que eu acho que nós ainda temos que esperar um pouco, enquanto a humanidade for a humanidade. Quer seja no domínio dos computadores ou no domínio das línguas e tradução, vai sempre ser preciso termos pessoas pra utilizar essas máquinas. Como diz o Stiglitz, o prêmio Nobel de economia, o que se chama agora de inteligência artificial há duas coisas: há pessoas, infelizmente, que vão perder empregos porque não têm uma qualificação que seja superior ao que a máquina faz, e há os outros que têm uma qualificação superior e as máquinas vão ser uma ajuda, vão ser uma coisa positiva para eles. No que diz respeito à tradução, é por isso que eu acho muito importante bem formar nossos estudantes, para eles terem um nível com que eles possam utilizar as máquinas de maneira positiva e não estar em concorrência com elas, e isso também é um programa muito importante do domínio da prática, do profissionalismo dos nossos estudantes, e também no que diz respeito às pesquisas interdisciplinares que aí há muito o que fazer visto as transformações da globalização. Quem teria acreditado há uns dez anos que o inglês já não seria a língua da internet, ou nos desenvolvimentos da inteligência artificial, ou o fato de que agora há um bilhão e 300 milhões de turistas, enquanto nos anos 50 só havia 25 ou 50 milhões. Todas essas transformações estão ocorrendo numa velocidade incrível, são coisas que precisam de máquinas, mas também de pessoas para pensar a complexidade do mundo onde a gente vive. 
AF: Muito obrigado, e espero ter a oportunidade de em breve tê-lo na USP falando pessoalmente.

MO: Obrigado eu, obrigado eu, claro.

TradTerm, São Paulo, v. 33, junho/2019, p. 168-177 www.revistas.usp.br/tradterm 